\title{
Comparative Study between ARX and ARMAX System Identification
}

\author{
Farzin Piltan, Shahnaz TayebiHaghighi \\ Intelligent Systems and Robotics Lab, Iranian Institute of Advanced Science and Technology (IRAN SSP), Shiraz/Iran \\ E-mail: Piltan_f@iranssp.org, WWW.Iranssp.org/english \\ Nasri B. Sulaiman \\ Department of Electrical and Electronic Engineering, Faculty of Engineering, University Putra Malaysia, Malaysia \\ E-mail: nasri@eng.upm.edu.my
}

\begin{abstract}
System Identification is used to build mathematical models of a dynamic system based on measured data. To design the best controllers for linear or nonlinear systems, mathematical modeling is the main challenge. To solve this challenge conventional and intelligent identification are recommended. System identification is divided into different algorithms. In this research, two important types algorithm are compared to identifying the highly nonlinear systems, namely: AutoRegressive with eXternal model input (ARX) and Auto Regressive moving Average with eXternal model input (Armax) Theory. These two methods are applied to the highly nonlinear industrial motor.
\end{abstract}

Index Terms - System identification, highly nonlinear dynamic equations, Arx system identification algorithm, Armax system identification algorithm.

\section{SYSTEM’s Data COLLECTION}

It is a well known fact that real physical systems (engineering systems) are very often uncertain or vague, which generally makes it difficult to accurately model a complex system or process by a mathematical model. Uncertainty means the exact output of a real physical system cannot be predicted by a mathematical model that describes the physical system under investigation, even if the input to the system is known. Uncertainty arises from two sources: unknown or unpredictable inputs (e.g., disturbance, noise) and unknown or unpredictable dynamics. Dynamic models are used for many purposes, to explain system behavior, for control design (i.e., model-based control) and for simulation. As a particular field of application, in motion control of robot manipulators, a dynamic model determines the control inputs needed to realize a reference motion and it also enables an analysis of how particular dynamic effects influence overall robot manipulator behavior. It is therefore important to model system dynamics. Since the model of a system dynamics can at best be an approximation of real physical systems, it will only capture some properties of real system.

Motors are very important instruments in any industries. The applications of motors are wide such as, pumping fluids, compressors and position movement. Servos motor and stepper motors are two important motors for position control. To detect the position servo motors are used. In this types of motors two parameters can control: angular position and velocity. In this type of motor, the output's position is controlled by potentiometer. This potentiometer is used to detect the required voltage and send to motor's output to select the desired position with the minimum error. Figure 1 shows the application of servo motors and feedback loop [1-5].

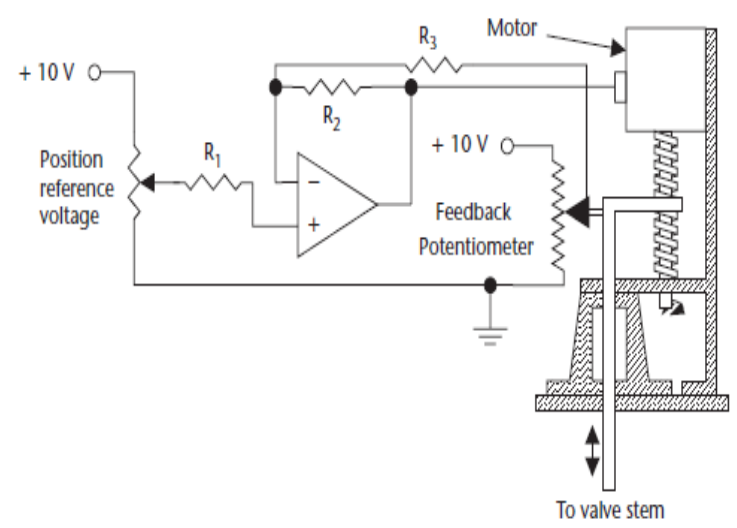

Fig.1. The Servo Motor

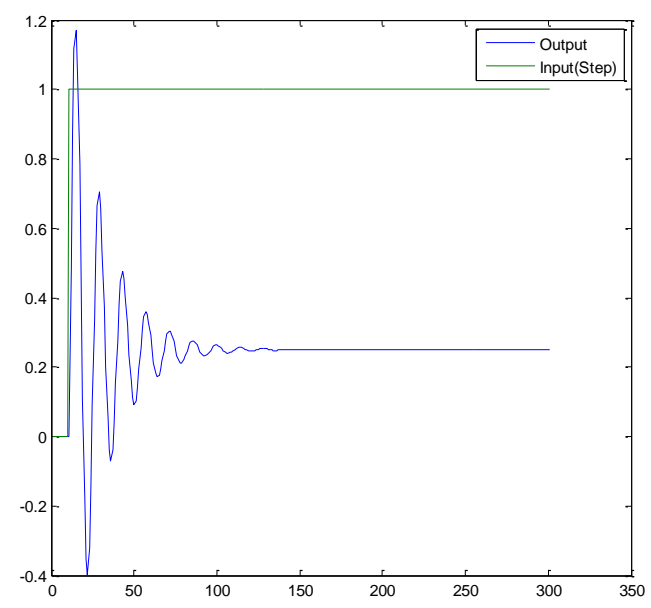

Fig.2. Behavior of Step Function system input-output Modeling 


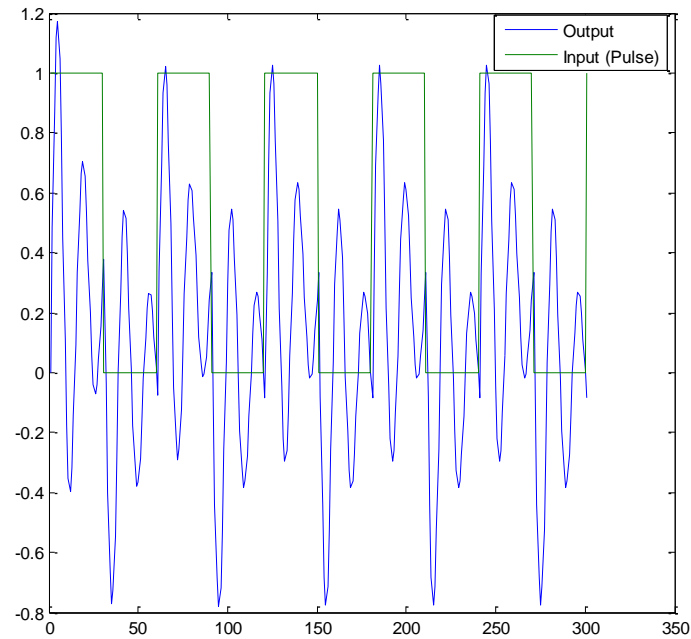

Fig.3. Behavior of Pulse Function system input-output Modeling

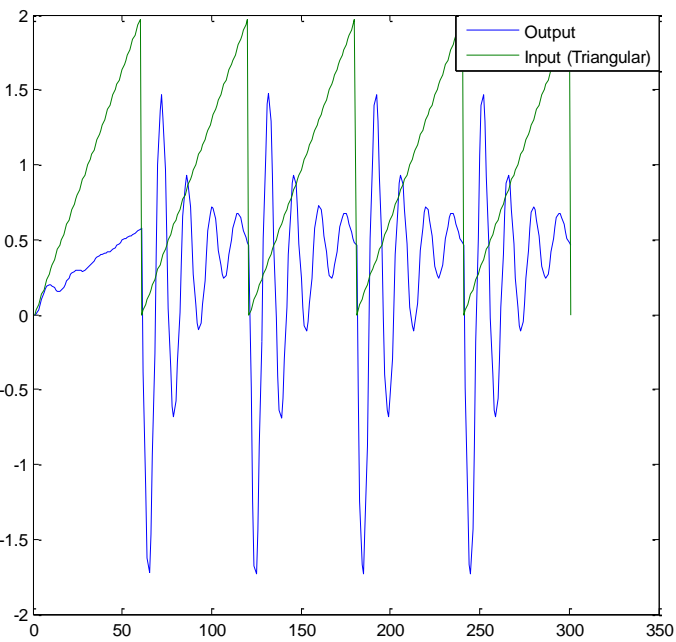

Fig.4. Behavior of Triangular Function system input-output Modeling

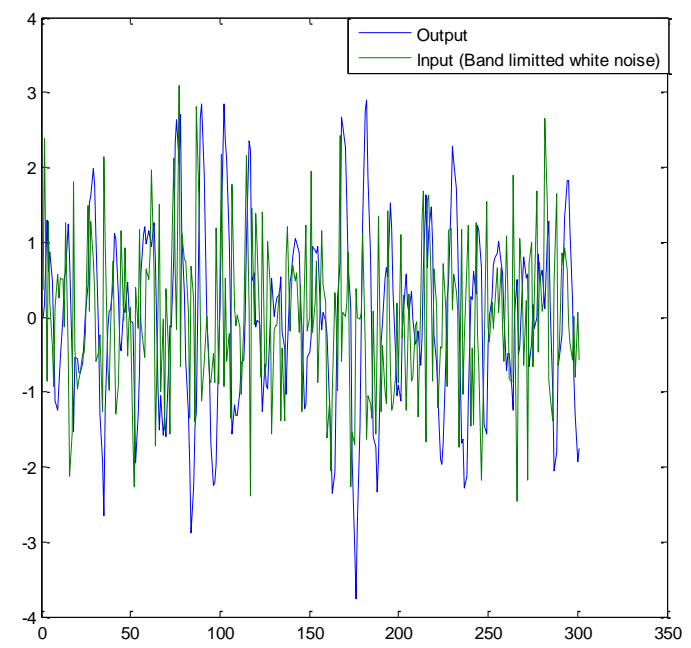

Fig.5. Behavior of Band limited white noise Function system inputoutput Modeling

Figure 2 shows the behavior of input-output data modeling in step input.

Figure 3 shows the pulse input-output behavior system modeling.

Figure 4 shows the triangular input-output behavior system modeling.

Finally in Figure 6, the input random number inputoutput behavior system is modeling.

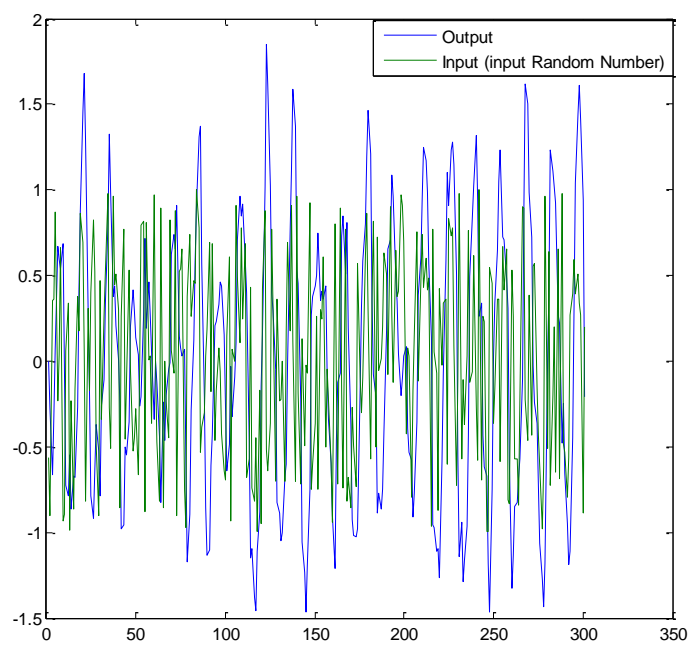

Fig.6. Behavior of input random number Function system input-output Modeling

\section{ARX SYSTEM'S IDENTIFICATION}

The system modeling and identification is divided into two main groups:

1. Traditional system identification

2. Intelligent system identification.

The classical logical methods of modeling, reasoning, and computing are deterministic. A statement can be true or false and nothing in between, or a variable can be expressed in binary terms ( 0 or 1 , yes or no). For example, in two-valued logic the propositions can take on only two truth values "true" or "false." The traditional system identification (modeling) are divided into following categories [6-10]:

1. ARX modeling

2. OE modeling

3. ARMAX modeling

4. FIR modeling

5. Box-Jenkins modeling

In real world, uncertainty is presents in every phenomenon and challenges every claim one makes. As an attempt to deal with uncertainties and account for the concept of partial truth, another type of logic called fuzzy logic (FL) was proposed by Zadeh. The fuzzy logic is based on the remarkable ability of the human brain in approximate reasoning, in an environment of uncertainty and imprecision. With this definition of FL, precise reasoning can be viewed as a limiting case of approximate reasoning. Unlike the classical logic, fuzzy logic allows partial truth and 
it also allows for values between 0 and 1. FL provides approximation capabilities (human way of approach) to capture uncertainties which cannot be described by precise mathematical models. The modeling aspect of FL has been employed by the control community either to model a controller itself (e.g., modeling the actions of a human operator that controls a machine), or a complex and uncertain phenomenon in the systems to be controlled (e.g., nonlinearities of robot manipulator dynamics) maybe precisely and rigorously. The intelligent modeling is divided into following methods [11-15]:

\section{Fuzzy Modeling}

2. Neural network modeling

3. Neuro fuzzy modeling

4. Genetic algorithm modeling

The general input-output form is:

$$
A(q) y(t)=\frac{B(q)}{F(q)} u(t-n k)+\frac{C(q)}{D(q)} e(t)
$$

Is defined by the five polynomials $A(q), B(q), C(q), D(q)$ and $F(q)$. In this state $A$ is:

$$
A(q)=\left[\begin{array}{llllll}
1 & a_{1} & a_{2} & a_{3} & \ldots & a_{n}
\end{array}\right]
$$

The most used model structure is the simple linear difference equation:

$$
\begin{aligned}
y(t)+a_{1} y(t-1) & +a_{2} y(t-2)+\cdots+a_{n a} y(t-n a) \\
& =b_{1} u(t-1)+b_{2} u(t-2)+\cdots \\
& +b_{n b} y(t-n k-n b+1)
\end{aligned}
$$

which relates the current output $y(t)$ to a finite number of past outputs $y(t-k)$ and inputs $u(t-k)$.

The structure is thus entirely defined by the three integers na, nb, and nk. na is equal to the number of poles and $n b-1$ is the number of zeros, while nk is the pure time-delay (the dead-time) in the system. For a system under sampled-data control, typically nk is equal to 1 if there is no dead-time. For multi-input systems nb and nk are row vectors, where the i-th element gives the order/delay associated with the i-th input [14-15]. To ARX modeling we have:

$$
A(q) y(t)=B(q) u(t-n k)+e(t)
$$

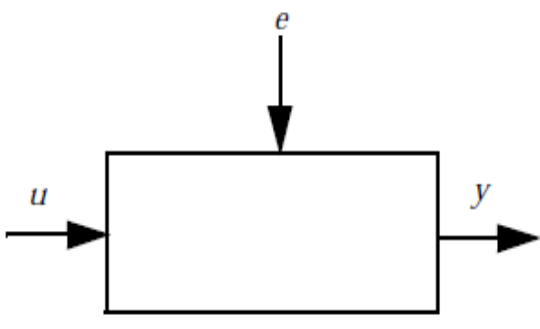

Fig.7. Input-Output Configuration
To ARX modeling three factors are important: inputs, noise and output. Figure 7 shows the basic input-output configuration [12-15].

Assuming the signals are related by a linear system, the relationship can be written

$$
\vec{y}(t)=G(q) U(t)+e(t)
$$

where $q$ is the shift operator and $\mathrm{G}(\mathrm{q}) . \mathrm{U}(\mathrm{t})$ is short for:

$$
G(q) U(t)=\sum g(k) \cdot U(t-k)
$$

and

$$
\mathrm{G}(\mathrm{q})=\sum \mathrm{g}(\mathrm{k}) \mathrm{q}^{-\mathrm{k}}, \mathrm{q}^{-1} \mathrm{u}(\mathrm{t})=\mathrm{u}(\mathrm{t}-1)
$$

The parameters of the ARX model structure is:

$$
A(q) y(t)=B(q) u(t)+e(t)
$$

The order in ARX modeling is:

$$
\mathrm{nn}=[\mathrm{na} \mathrm{nb} \mathrm{nk}]
$$

Where na is output order in ARX, nb is input order in $\mathrm{ARX}$ and nc is delay order. The nn in ARX identification is [l $\left.\begin{array}{lll}2 & 2 & 1\end{array}\right]$.

Discrete-time IDPOLY model in ARX for step input is:

$$
\begin{gathered}
A(q) y(t)=B(q) u(t)+e(t) \\
A(q)=1-1.718 q^{-1}+0.9048 q^{-2} \\
B(q)=0.4839 q^{-1}-0.4371 q^{-2}
\end{gathered}
$$

In this identification the, Loss function $6.51358 e-$ 031 and FPE $6.68669 e-031$

The fitting between input/output is $100 \%$ as Figure 8 .

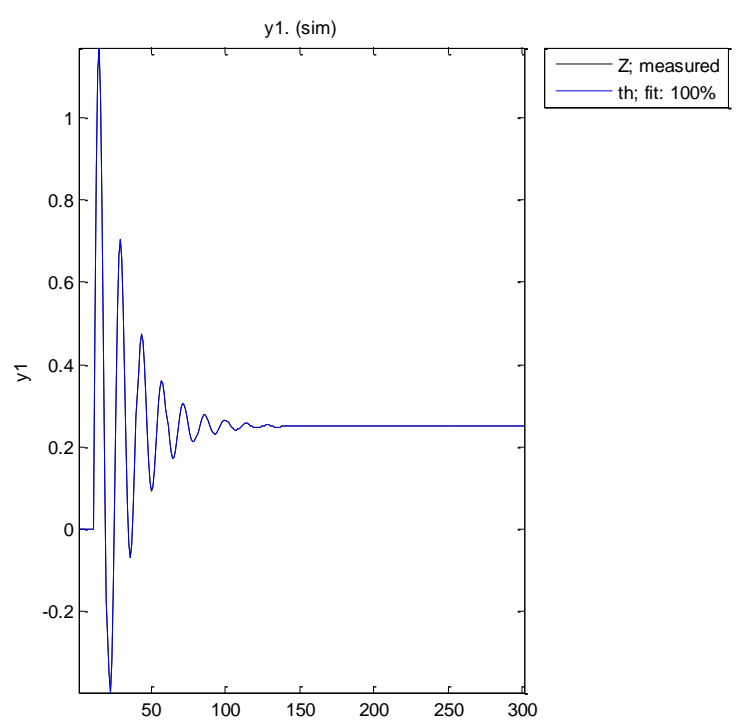

Fig.8. Fitting test compare between ARX identification and output 
Figure 9 shows the error between estimate identification system and real output.

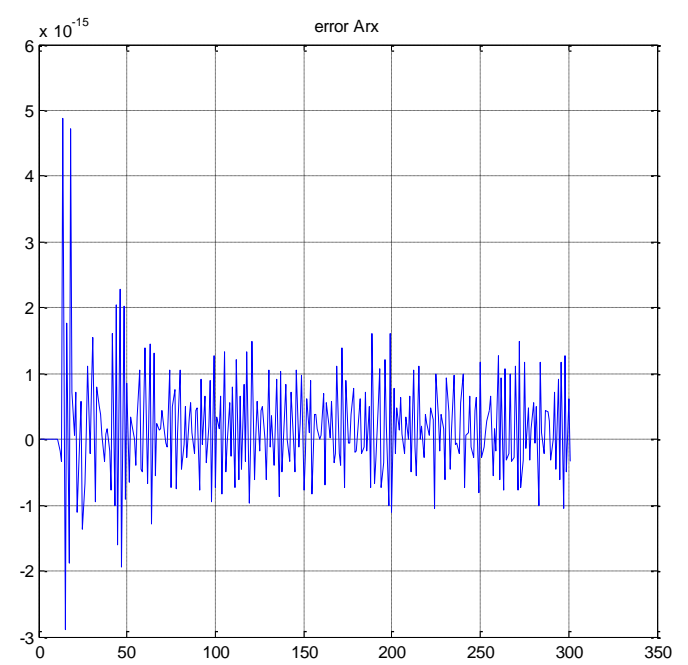

Fig.9. Error test compare between ARX identification and output

Discrete-time IDPOLY model ARX modeling for pulse input is:

$$
\begin{gathered}
A(q) y(t)=B(q) u(t)+e(t) \\
A(q)=1-1.718 q^{-1}+0.9048 q^{-2} \\
B(q)=0.4839 q^{-1}-0.4371 q^{-2}
\end{gathered}
$$

Loss function 1.66081e-015 and FPE 1.70495e-015.

The fitting between input/output is $100 \%$ based on Figure 10.

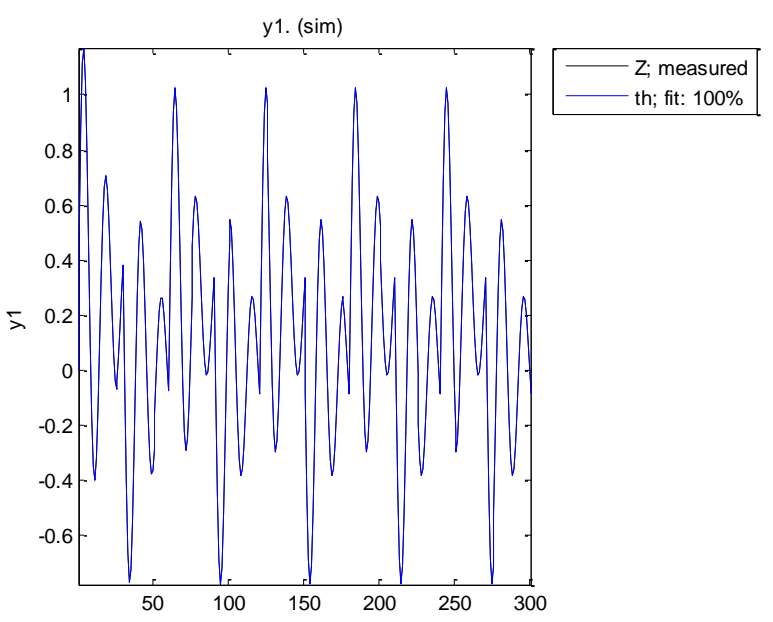

Fig.10. Fitting test compare between ARX identification and output (Pulse input)

Figure 11 shows the error between estimate identification system and real output in pulse input.

Discrete-time IDPOLY model ARX modeling for ramp input is:

$$
A(q) y(t)=B(q) u(t)+e(t)
$$

$$
\begin{gathered}
A(q)=1-1.718 q^{-1}+0.9049 q^{-2} \\
B(q)=0.4818 q^{-1}-0.4342 q^{-2}
\end{gathered}
$$

Loss function is 1.26637e-006 and FPE is 1.30003e006.

The fitting between input/output is $99.11 \%$ based on Figure 12.

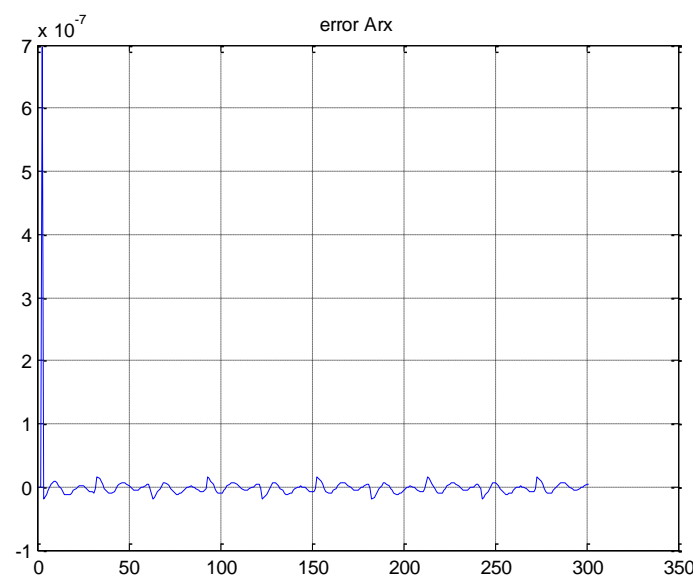

Fig.11. Error test compare between ARX identification and output in pulse input

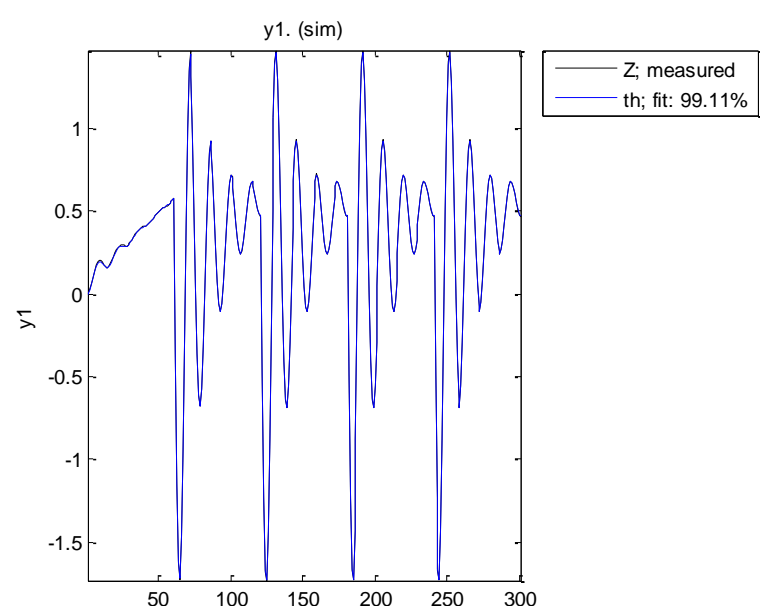

Fig.12. Fitting test compare between ARX identification and output (Ramp input)

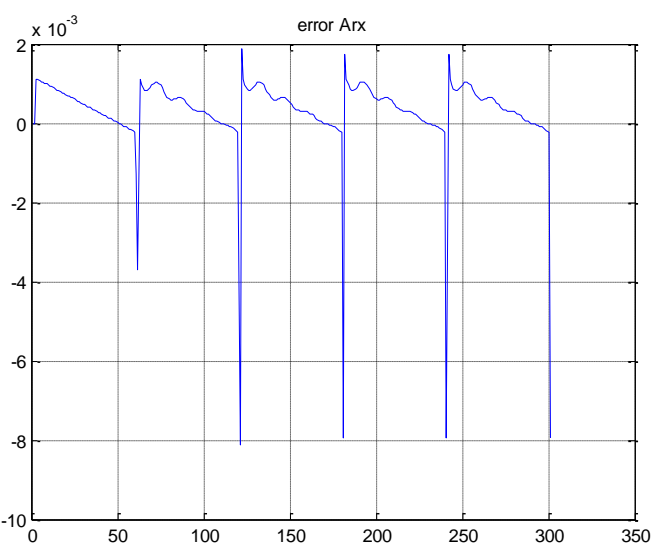

Fig.13. Error test compare between ARX identification and output in ramp input

I.J. Intelligent Systems and Applications, 2017, 2, 25-34 
Discrete-time IDPOLY model ARX modeling for band limited white noise input is:

$$
\begin{gathered}
A(q) y(t)=B(q) u(t)+e(t) \\
A(q)=1-1.718 q^{-1}+0.9048 q^{-2} \\
B(q)=0.4839 q^{-1}-0.4371 q^{-2}
\end{gathered}
$$

Loss function is $2.25909 \mathrm{e}-016$ and FPE is $2.31913 \mathrm{e}-$ 016.

The fitting between input/output is $100 \%$ based on Figure 14.

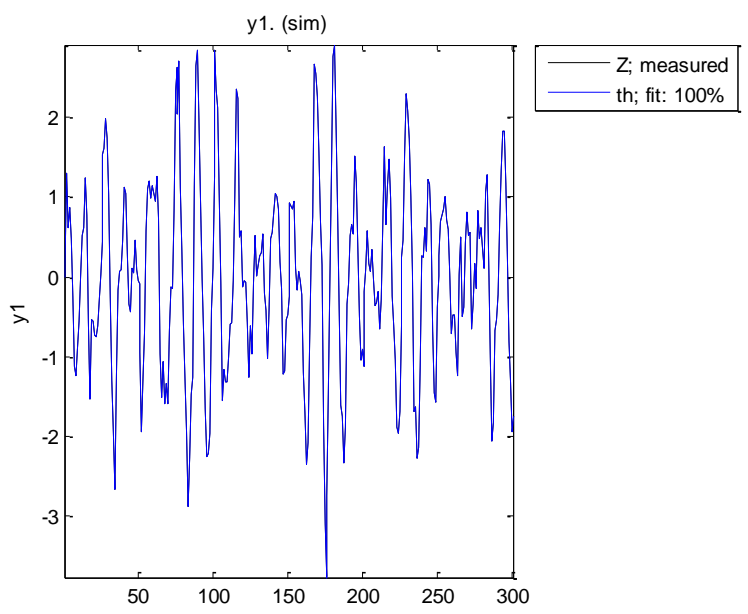

Fig.14. Fitting test compare between ARX identification and output (Band limited white noise)

Figure 15 shows the error between estimate identification system and real output in band limited white noise input.

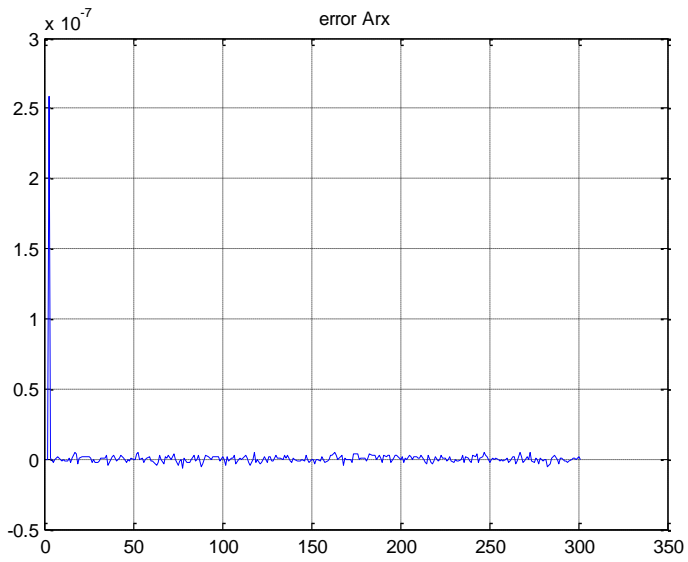

Fig.15. Error test compare between ARX identification and output in band limited white noise input

Discrete-time IDPOLY model ARX modeling for input random numbers is:

$$
\begin{gathered}
A(q) y(t)=B(q) u(t)+e(t) \\
A(q)=1-1.718 q^{-1}+0.9048 q^{-2}
\end{gathered}
$$

$$
B(q)=0.4839 q^{-1}-0.4371 q^{-2}
$$

Loss function is $5.65716 \mathrm{e}-016$ and FPE is 5.80752e016.

The fitting between input/output is $100 \%$ based on Figure 16.

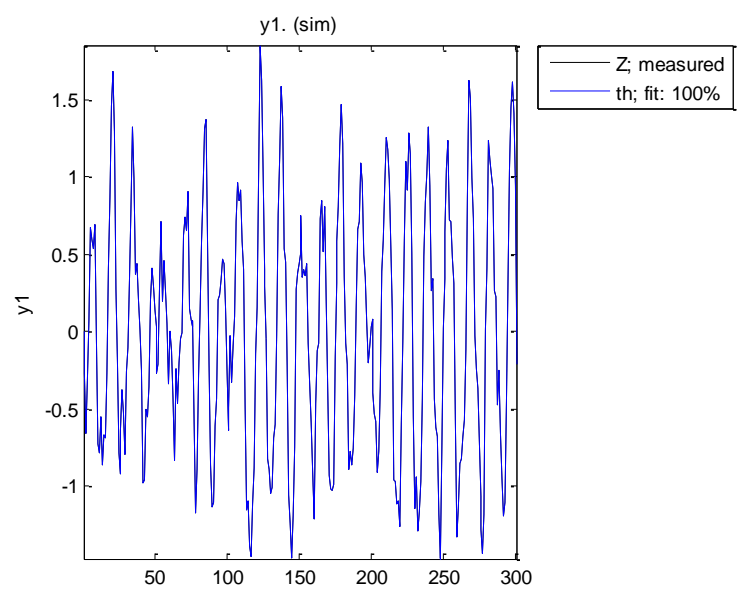

Fig.16. Fitting test compare between ARX identification and output (Input Random Number)

Figure 17 shows the error between estimate identification system and real output in input random number test.

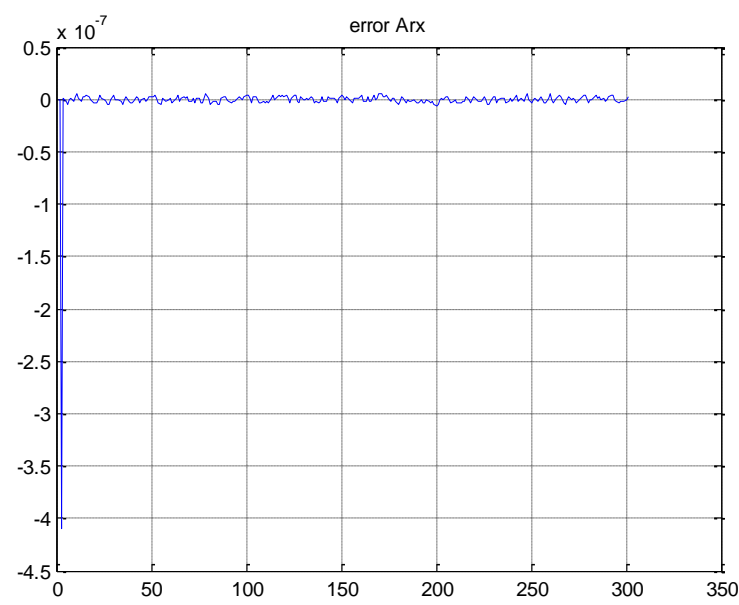

Fig.17. Error test compare between ARX identification and output in input random number input

The Discrete-time IDPOLY ARMAX model is:

$$
A(q) y(t)=B(q) u(t)+C(q) e(t)
$$

where

$$
\begin{gathered}
A(q)=1-1.718 q^{-1}+0.9048 q^{-2} \\
B(q)=0.4839 q^{-1}-0.4371 q^{-2} \\
C(q)=1+0.7278 q^{-1}+q^{-2}
\end{gathered}
$$


Loss function $1.30582 e-027$ and FPE 1.35822e027.

Based on ARX system identification the $\mathrm{S}$ domain transfer function and $\mathrm{Z}$ domain transfer functions are:

$$
\begin{gathered}
H(s)=\frac{0.5 s+0.05}{s^{2}+0.1 s+0.2} \\
H(z)=\frac{0.4839 Z-0.4371}{Z^{2}-1.7177 Z+0.9048}
\end{gathered}
$$

\section{ARMAX SYSTEM'S IDENTIFICATION}

The general input-output form is:

$$
A(q) y(t)=\frac{B(q)}{F(q)} u(t-n k)+\frac{C(q)}{D(q)} e(t)
$$

The parameters of the ARMAX model structure is:

$$
A(q) y(t)=B(q) u(t)+C(q) e(t)
$$

The order in ARMAX modeling is:

$$
\mathrm{nn}=[\text { na nb nc nk }]
$$

Where na is output order in ARMAX, nb is input order in ARMAX, nc is the noise order and nk is the delay order and the nn in ARMAX identification is [l $\left.\begin{array}{llll}2 & 2 & 1 & 1\end{array}\right]$.

The Discrete-time IDPOLY ARMAX model for step input is:

$$
A(q) y(t)=B(q) u(t)+C(q) e(t)
$$

where

$$
\begin{gathered}
A(q)=1-1.718 q^{-1}+0.9048 q^{-2} \\
B(q)=0.4839 q^{-1}-0.4371 q^{-2} \\
C(q)=1+0.0336 q^{-1}+0.2794 q^{-2}
\end{gathered}
$$

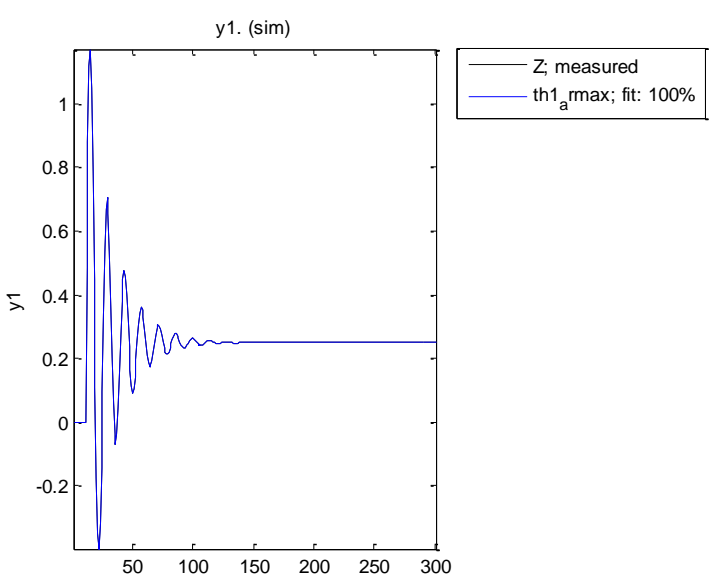

Fig.18. Fitting test compare between ARMAX identification and output

Loss function $6.20333 e-031$ and FPE 6.45653e-
031.

The fitting between input/output is $100 \%$ as Figure 18 .

Figure 19 shows the error between estimate identification system and real output in ARMAX modeling.

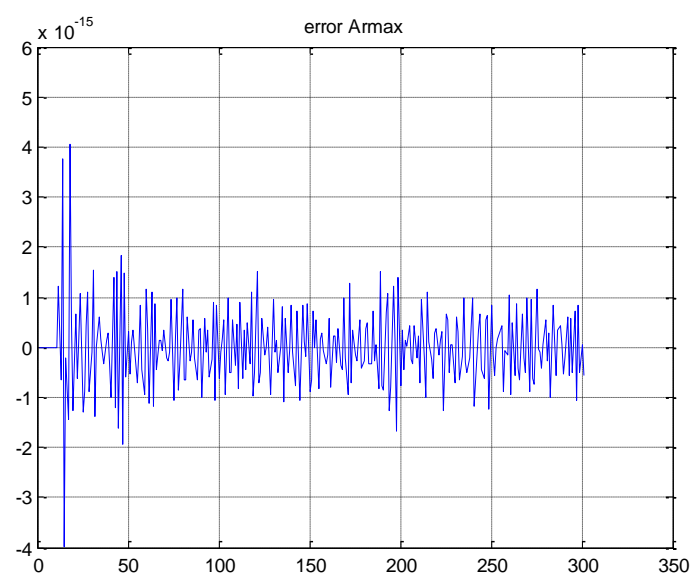

Fig.19. Error test compare between ARMAX identification and output

Regarding to final predictive error (FPE) for ARX and ARMAX in step input, ARMAX modelling is better than ARX in this type of input.

The Discrete-time IDPOLY ARMAX model for pulse input is:

$$
A(q) y(t)=B(q) u(t)+C(q) e(t)
$$

where

$$
\begin{gathered}
A(q)=1-1.718 q^{-1}+0.9048 q^{-2} \\
B(q)=0.4839 q^{-1}-0.4371 q^{-2} \\
C(q)=1+0.6501 q^{-1}+q^{-2}
\end{gathered}
$$

Loss function $1.48899 e-027$ and FPE $1.54875 e-$ 027.

The fitting between input/output is $100 \%$ for pulse input ARMAX modeling shows in Figure 20.

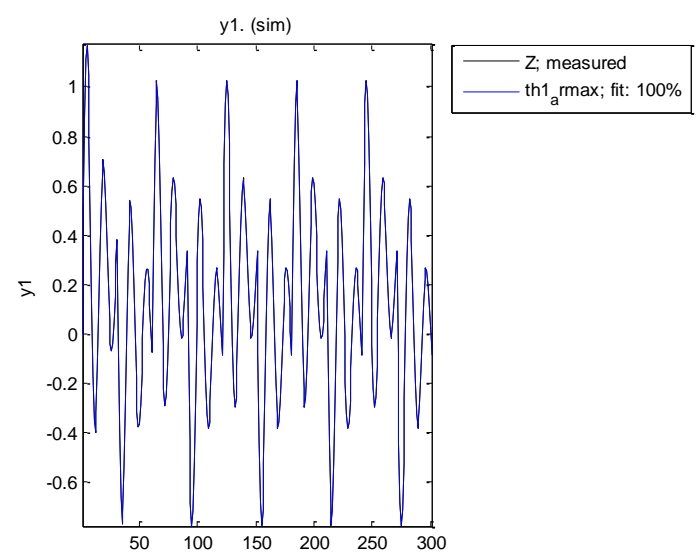

Fig.20. Fitting test compare between ARMAX identification and output (pulse input) 
Figure 21 shows the error between estimate identification system and real output in ARMAX modeling in pulse modeling.

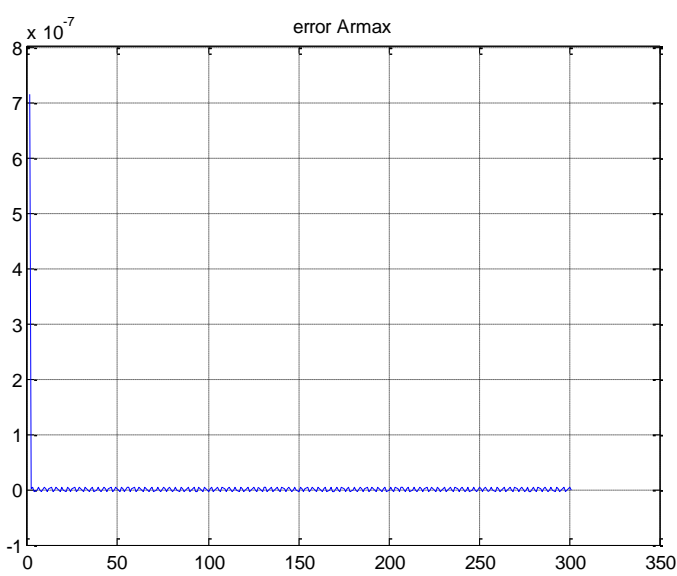

Fig.21. Error test compare between ARMAX identification and output in pulse input

Regarding to final predictive error (FPE) for ARX and ARMAX in pulse input, ARMAX modelling is better. The Discrete-time IDPOLY ARMAX model for ramp input is:

$$
A(q) y(t)=B(q) u(t)+C(q) e(t)
$$

where

$$
\begin{gathered}
A(q)=1-1.717 q^{-1}+0.9045 q^{-2} \\
B(q)=0.481 q^{-1}-0.4336 q^{-2} \\
C(q)=1+0.2618 q^{-1}+0.1648 q^{-2}
\end{gathered}
$$

Loss function 1.19057e - 006 and FPE 1.23835e006. The fitting between input/output is $98.86 \%$ for ramp input ARMAX modeling shows in Figure 22.

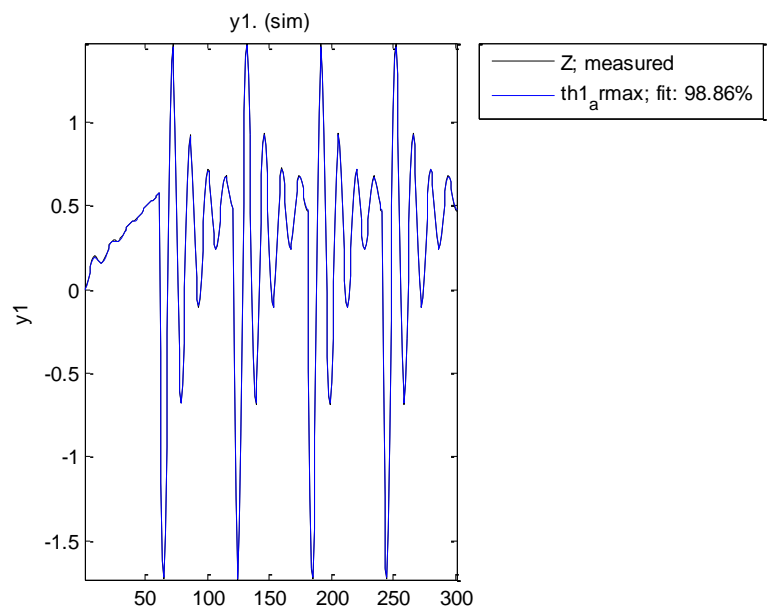

Fig.22. Fitting test compare between ARMAX identification and output (ramp input)

Figure 23 shows the error between estimate identification system and real output in ARMAX modeling in ramp modeling.

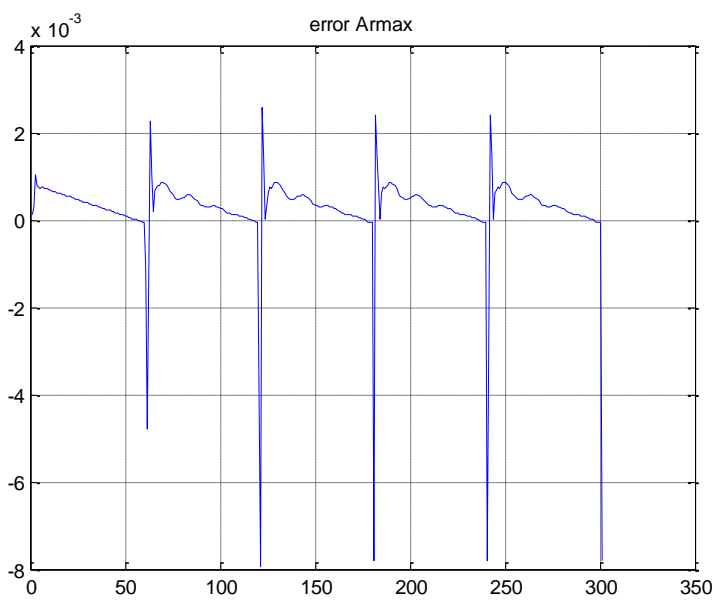

Fig.23. Error test compare between ARMAX identification and output in ramp input

Regarding to final predictive error (FPE) for ARX and ARMAX in ramp input, ARMAX modelling is better. The Discrete-time IDPOLY ARMAX model for band limited white noise is:

$$
A(q) y(t)=B(q) u(t)+C(q) e(t)
$$

where

$$
\begin{gathered}
A(q)=1-1.718 q^{-1}+0.9048 q^{-2} \\
B(q)=0.4839 q^{-1}-0.4371 q^{-2} \\
C(q)=1+q^{-1}-1.577 e-005 q^{-2}
\end{gathered}
$$

Loss function 7.36336e - 024 and FPE 7.65888e 024.

The fitting between input/output is $100 \%$ for band limited white noise input ARMAX modeling shows in Figure 24.

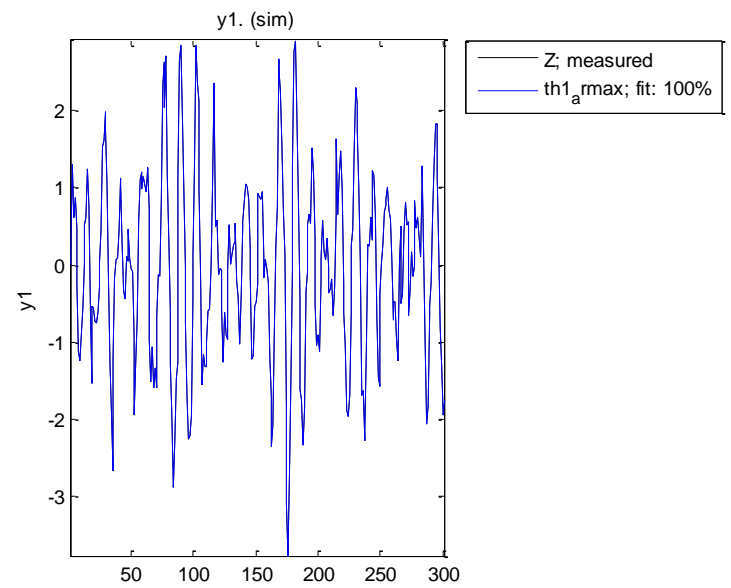

Fig.24. Fitting test compare between ARMAX identification and output (band limited white noise input) 
Figure 25 shows the error between estimate identification system and real output in ARMAX modeling in band limited white noise modeling.

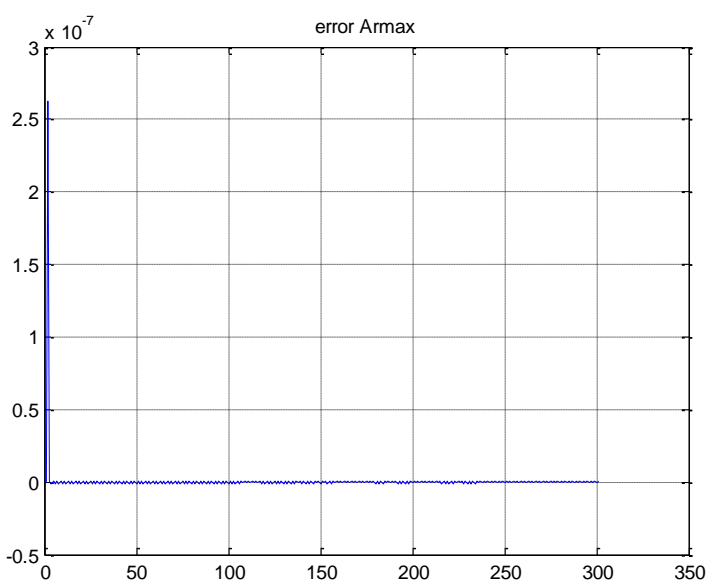

Fig.25. Error test compare between ARMAX identification and output in band limited white noise input

Regarding to final predictive error (FPE) for ARX and ARMAX in band limited white noise input, ARMAX modelling is better.

The Discrete-time IDPOLY ARMAX model input random number is:

$$
A(q) y(t)=B(q) u(t)+C(q) e(t)
$$

where

$$
\begin{gathered}
A(q)=1-1.718 q^{-1}+0.9048 q^{-2} \\
B(q)=0.4839 q^{-1}-0.4371 q^{-2} \\
C(q)=1+0.7278 q^{-1}+q^{-2}
\end{gathered}
$$

Loss function $1.30582 e-027$ and FPE $1.35822 e-$ 027. The fitting between input/output is $100 \%$ for random numbers input ARMAX modeling shows in Figure 26.

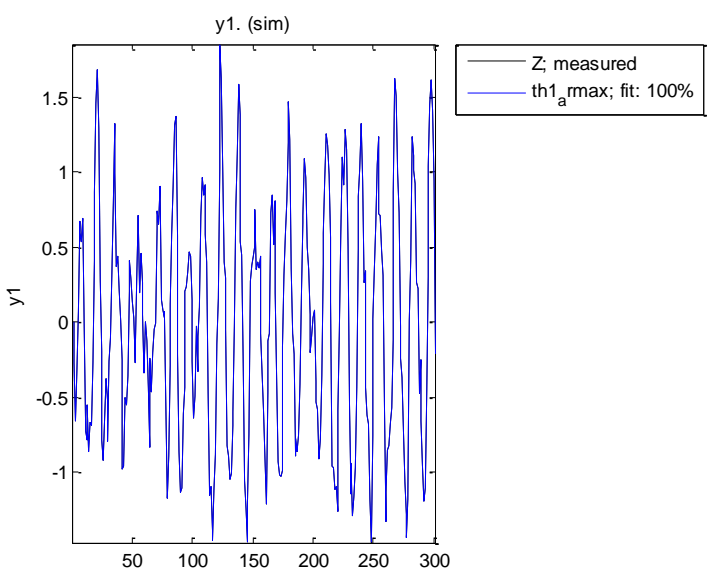

Fig.26. Fitting test compare between ARMAX identification and output (random numbers input)
Figure 27 shows the error between estimate identification system and real output in ARMAX modeling in random numbers input modeling.

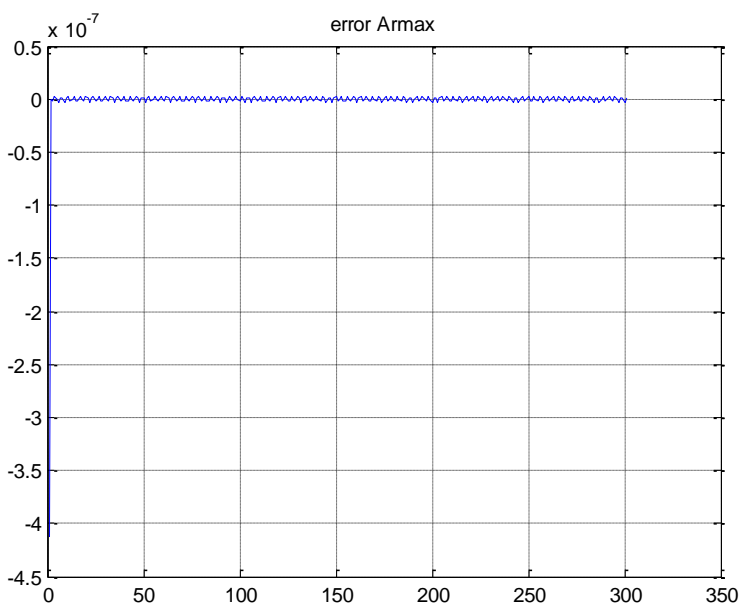

Fig.27. Error test compare between ARMAX identification and output in random numbers input

Regarding to final predictive error (FPE) for ARX and ARMAX in random numbers input, ARMAX modelling is better. Based on system ARMAX identification the $S$ domain transfer function and $\mathrm{Z}$ domain transfer functions are:

$$
H(s)=\frac{0.5 s+0.05}{s^{2}+0.1 s+0.2}
$$

\begin{tabular}{|c|c|c|c|c|c|c|}
\hline system & a1 & $\mathrm{a} 2$ & b1 & b2 & $\mathrm{c} 1$ & $\mathrm{c} 2$ \\
\hline $\begin{array}{l}\text { ARX } \\
\text { Step }\end{array}$ & $\begin{array}{c}- \\
1.718\end{array}$ & 0.9048 & 0.4839 & $\begin{array}{c}- \\
0.4371\end{array}$ & & \\
\hline $\begin{array}{l}\text { ARMAX } \\
\text { Step }\end{array}$ & $\begin{array}{c}- \\
1.718\end{array}$ & 0.9048 & 0.4839 & $\begin{array}{c}- \\
0.4371\end{array}$ & 0.0336 & 0.2794 \\
\hline $\begin{array}{l}\text { ARX } \\
\text { Pulse }\end{array}$ & $\begin{array}{c}- \\
1.718\end{array}$ & 0.9048 & 0.4839 & $\begin{array}{c}- \\
0.4371\end{array}$ & & \\
\hline $\begin{array}{l}\text { ARMAX } \\
\text { Pulse }\end{array}$ & $\begin{array}{c}- \\
1.718\end{array}$ & 0.9048 & 0.4839 & $\begin{array}{c}- \\
0.4371\end{array}$ & 0.6501 & 1 \\
\hline $\begin{array}{c}\text { ARX } \\
\text { Ramp }\end{array}$ & $\begin{array}{c}- \\
1.718\end{array}$ & 0.9049 & 0.4818 & $\begin{array}{c}- \\
0.4342\end{array}$ & & \\
\hline $\begin{array}{c}\text { ARMAX } \\
\text { Ramp }\end{array}$ & $\begin{array}{c}- \\
1.717\end{array}$ & 0.9045 & 0.481 & $\begin{array}{c}- \\
0.4336\end{array}$ & 0.2618 & 0.1648 \\
\hline $\begin{array}{c}\text { ARX } \\
\text { White } \\
\text { noise }\end{array}$ & $\begin{array}{c}- \\
1.718\end{array}$ & 0.9048 & 0.4839 & $\begin{array}{c}- \\
0.4371\end{array}$ & & \\
\hline $\begin{array}{c}\text { ARMAX } \\
\text { White } \\
\text { noise }\end{array}$ & $\begin{array}{c}- \\
1.718\end{array}$ & 0.9048 & 0.4839 & $\begin{array}{c}- \\
0.4371\end{array}$ & 1 & $\begin{array}{c}- \\
1.57 \mathrm{e}- \\
5\end{array}$ \\
\hline $\begin{array}{c}\text { ARX } \\
\text { Random } \\
\text { number }\end{array}$ & $\begin{array}{c}- \\
1.718\end{array}$ & 0.9048 & 0.4839 & $\begin{array}{c}- \\
0.4371\end{array}$ & & \\
\hline $\begin{array}{l}\text { ARMAX } \\
\text { Random } \\
\text { Number }\end{array}$ & $\begin{array}{c}- \\
1.718\end{array}$ & 0.9048 & 0.4839 & $\begin{array}{c}- \\
0.4371\end{array}$ & 0.7278 & 1 \\
\hline
\end{tabular}

$$
H(z)=\frac{0.4839 Z-0.4371}{Z^{2}-1.7177 Z+0.9048}
$$

Table 1 shows ARX and ARMAX parameter identification in five types of inputs.

Table.1. System's parameters Identification (ARX Vs ARMAX) 


\section{CONCLUSION}

Regarding to this research, system identification for highly nonlinear dynamic system (electric motor) is introduced. According to this research two methodologies are used for parameters identification: ARX modeling and ARMAX modeling. For data collection and data analysis, we have five types input-output regarding to this dynamic system. In final predictive error point of view, ARMAX modeling has better performance in comparison to ARX modeling. This methodology is important to design high performance controller for this electric motor.

\section{REFERENCE}

[1] Jami'in, M. A., Hu, J., Marhaban, M. H., Sutrisno, I., \& Mariun, N. B. (2016). Quasi - ARX neural network based adaptive predictive control for nonlinear systems. IEEJ Transactions on Electrical and Electronic Engineering, 11(1), 83-90.

[2] Sar, A., \& Kural, A. (2015, November). Modeling and ARX identification of a quadrotor MiniUAV. In 2015 9th International Conference on Electrical and Electronics Engineering (ELECO) (pp. 1196-1200). IEEE.

[3] Hartmann, A., Lemos, J. M., Costa, R. S., Xavier, J., \& Vinga, S. (2015). Identification of switched ARX models via convex optimization and expectation maximization. Journal of Process Control, 28, 9-16.

[4] Rincón, F. D., Le Roux, G. A., \& Lima, F. V. (2015). A novel ARX-based approach for the steady-state identification analysis of industrial depropanizer column datasets. Processes, 3(2), 257-285.

[5] Folgheraiter, M. (2016). A combined B-spline-neuralnetwork and ARX model for online identification of nonlinear dynamic actuation systems. Neurocomputing, 175, 433-442.

[6] Ahmad A. Mahfouz, Mohammed M. K., Farhan A. Salem,"Modeling, Simulation and Dynamics Analysis Issues of Electric Motor, for Mechatronics Applications, Using Different Approaches and Verification by MATLAB/Simulink", International Journal of Intelligent Systems and Applications(IJISA), Vol.5, No.5, pp.39-57, 2013.DOI: 10.5815/ijisa.2013.05.06.

[7] Santosh Kumar Nanda, Debi Prasad Tripathy, Simanta Kumar Nayak, Subhasis Mohapatra,"Prediction of Rainfall in India using Artificial Neural Network (ANN) Models", International Journal of Intelligent Systems and Applications(IJISA), Vol.5, No.12, pp.1-22, 2013. DOI: 10.5815/ijisa.2013.12.01.

[8] Nikolay Karabutov,"Structural Identification of Systems with Distributed Lag", International Journal of Intelligent Systems and Applications (IJISA), Vol.5, No.11, pp.1-10, 2013. DOI: 10.5815/ijisa.2013.11.01.

[9] Dragan Antić, Miroslav Milovanović, Saša Nikolić, Marko Milojković, Staniša Perić,"Simulation Model of Magnetic Levitation Based on NARX Neural Networks", International Journal of Intelligent Systems and Applications (IJISA), Vol.5, No.5, pp.25-32, 2013.DOI: 10.5815/ijisa.2013.05.04.

[10] Ljung, Lennart. "System identification." Signal Analysis and Prediction. Birkhäuser Boston, 1998. 163-173.

[11] Nelles, Oliver. Nonlinear system identification: from classical approaches to neural networks and fuzzy models. Springer Science \& Business Media, 2013.

[12] Oomen, Tom, et al. "Connecting system identification and robust control for next-generation motion control of a wafer stage." IEEE Transactions on Control Systems Technology 22.1 (2014): 102-118.

[13] Liu, Lezhang, et al. "Integrated system identification and state-of-charge estimation of battery systems." IEEE Transactions on Energy Conversion28.1 (2013): 12-23.

[14] Dorobantu, Andrei, et al. "System identification for small, low-cost, fixed-wing unmanned aircraft." Journal of Aircraft 50.4 (2013): 1117-1130.

[15] Fuggini, C., E. Chatzi, and D. Zangani. "Combining Genetic Algorithms with a Meso - Scale Approach for System Identification of a Smart Polymeric Textile." Computer - Aided Civil and Infrastructure Engineering 28.3 (2013): 227-245.

\section{Authors' Profiles}

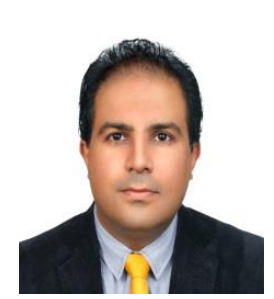

Farzin Piltan is an outstanding researcher and scientist in the field of Electronics and Control engineering with expertise in the areas of nonlinear systems, robotics, and microelectronic control. Mr. Piltan is an advanced degree holder in his field. Currently, Mr. Piltan is the Head of Mechatronics, Intelligent System, and Robotics Laboratory at the Iranian Institute of Advanced Science and Technology (IRAN SSP). Mr. Piltan led several high impact projects involving more than 150 researchers from countries around the world including Iran, Finland, Italy, Germany, South Korea, Australia, and the United States. Mr. Piltan has authored or co-authored more than 140 papers in academic journals, conference papers, and book chapters. His papers have been cited at least 3900 times by independent and dependent researchers from around the world including Iran, Algeria, Pakistan, India, China, Malaysia, Egypt, Columbia, Canada, United Kingdom, Turkey, Taiwan, Japan, South Korea, Italy, France, Thailand, Brazil and more. Moreover, Mr. Piltan has peer-reviewed at least 23 manuscripts for respected international journals in his field. Mr. Piltan will also serve as a technical committee member of the upcoming EECSI 2015 Conference in Indonesia. Mr. Piltan has served as an editorial board member or journal reviewer of several international journals in his field as follows: International Journal Of Control And Automation (IJCA), Australia, ISSN: 2005-4297, International Journal of Intelligent System and Applications (IJISA), Hong Kong, ISSN:2074-9058, IAES International Journal Of Robotics And Automation, Malaysia, ISSN:2089-4856, International Journal of Reconfigurable and Embedded Systems, Malaysia, ISSN:2089-4864. Mr. Piltan has acquired a formidable repertoire of knowledge and skills and established himself as one of the leading young scientists in his field. Specifically, he has accrued expertise in the design and implementation of intelligent controls in nonlinear systems. Mr. Piltan has employed his remarkable expertise in these areas to make outstanding contributions as detailed follows:Nonlinear control for industrial robot manipulator (2010-IRAN SSP), Intelligent Tuning The Rate Of Fuel Ratio In Internal Combustion Engine (2011-IRANSSP), Design High Precision and Fast Dynamic Controller For Multi-Degrees Of Freedom Actuator (2013-IRANSSP), Research on Full Digital Control for Nonlinear Systems (2011-IRANSSP), Micro-Electronic Based Intelligent Nonlinear Controller (2015-IRANSSP), Active Robot Controller for Dental Automation (2015IRANSSP), Design a Micro-Electronic Based Nonlinear Controller for First Order Delay System (2015-IRANSSP). 
The above original accomplishments clearly demonstrate that Mr. Piltan has performed original research and that he has gained a distinguished reputation as an outstanding scientist in the field of electronics and control engineering. Mr. Piltan has a tremendous and unique set of skills, knowledge, and background for his current and future work. He possesses a rare combination of academic knowledge and practical skills that are highly valuable for his work. In 2011, he published 28 firstauthor papers, which constitute about $30 \%$ of papers published by the Department of Electrical and Electronic Engineering at University Putra Malaysia. Additionally, his 28 papers represent about $6.25 \%$ and $4.13 \%$ of all control and system papers published in Malaysia and Iran, respectively, in 2011.

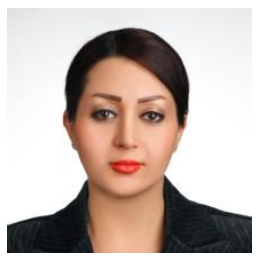

Shahnaz tayebihaghighi is currently research assistant at Institute of Advance Science and Technology, Research and Development Center, IRAN SSP. She is research assistant of team (47 researchers) to design and build of nonlinear control of industrial robot manipulator for experimental research and education and published 3 Papers in this field since 2010 to 2012, research assistant (9 researchers) to design and implement intelligent tuning the rate of fuel ratio in internal combustion engine for experimental research and education and published 1 Journal papers since 2011 to 20132015. Research assistant in project entitle: system modeling and identification Her current research interests are nonlinear control, artificial control system and applied to FPGA, system Identification and IC engine modeling and control.

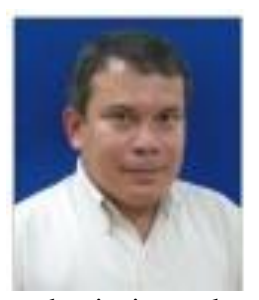

Dr. Nasri Sulaiman advisor and supervisor of several high impact projects involving more than 150 researchers from countries around the world including Iran, Malaysia, Finland, Italy, Germany, South Korea, Australia, and the United States. Dr. Nasri Sulaiman has authored or coauthored more than 80 papers in academic journals, conference papers and book chapters. His papers have been cited at least 3000 times by independent and dependent researchers from around the world including Iran, Algeria, Pakistan, India, China, Malaysia, Egypt, Columbia, Canada, United Kingdom, Turkey, Taiwan, Japan, South Korea, Italy, France, Thailand, Brazil and more. Dr. Nasri Sulaiman has employed his remarkable expertise in these areas to make outstanding contributions as detailed below:

- Design of a reconfigurable Fast Fourier Transform (FFT) Processor using multi-objective Genetic Algorithms (2008-UPM)

- Power consumption investigation in reconfigurable Fast Fourier Transform (FFT) processor (2010-UPM)

- Crest factor reduction And digital predistortion Implementation in Orthogonal frequency Division multiplexing (ofdm) systems (2011-UPM)

- High Performance Hardware Implementation of a MultiObjective Genetic Algorithm, (RUGS), Grant amount RM42,000.00, September (2012-UPM)

- Nonlinear control for industrial robot manipulator (2010IRAN SSP)

- Intelligent Tuning The Rate Of Fuel Ratio In Internal Combustion Engine (2011-IRANSSP)

- Design High Precision and Fast Dynamic Controller For
Multi-Degrees Of Freedom Actuator (2013-IRANSSP)

- Research on Full Digital Control for Nonlinear Systems (2011-IRANSSP)

- Micro-Electronic Based Intelligent Nonlinear Controller (2015-IRANSSP)

- Active Robot Controller for Dental Automation (2015IRANSSP)

- Design a Micro-Electronic Based Nonlinear Controller for First Order Delay System (2015-IRANSSP)

How to cite this paper: Farzin Piltan, Shahnaz TayebiHaghighi, Nasri B. Sulaiman,"Comparative Study between ARX and ARMAX System Identification", International Journal of Intelligent Systems and Applications(IJISA), Vol.9, No.2, pp.25-34, 2017. DOI: 10.5815/ijisa.2017.02.04 